\title{
Una falla geológica de fallas raciales: el Sur norteamericano en Piri Thomas y Manuel Zapata Olivella*
}

\author{
John Maddox ${ }^{1}$ \\ University of Alabama at Birmingham (EE.UU.)
}

\section{Resumen}

En los años 1940 dos afro-latinos hemisféricos, el afro-puertorriqueño Piri Thomas y el afro-colombiano Manuel Zapata Olivella, viajaron al Sur durante la época de las leyes discriminatorias Jim Crow y los linchamientos de negros. ¿Por qué se pusieron en peligro? Mi respuesta adapta el concepto de los "movimientos continentales" inter-americanos del crítico John D. "Río" Riofrío al contexto de Jim Crow para mostrar que el Sur norteamericano era una "zona catastrófica" a la cual viajaron estos escritores en su juventud para fortalecer sus identidades afro-latinas y su compromiso con la comunidad. Las confrontaciones de estos autores y sus protagonistas con la zona de desastre del Sur son relevantes mientras América experimenta el Nuevo Jim Crow y la época de Trump.

Palabras clave: afro-colombia, afro-latino, relatos de viaje, identidad, discriminación racial.

\section{Abstract}

In the 1940s two hemispheric Afro-Latinos, Afro-Puerto Rican Piri Thomas and Afro-Colombian Manuel Zapata Olivella, journeyed to the South of lynchings and Jim Crow. Why did they put themselves in peril? My answer adapts John D. "Rio" Riofrío's inter-American "continental shifts" to the Jim Crow context to show that the US South was a "disaster zone" to which these writers journeyed to in their youth to galvanize their diasporic and Afro-Latino identities and community solidarity. These authors and their protagonists' confrontations with the danger zone of the South are relevant as the Americas experience the New Jim Crow and the Trump era.

Keywords: Afro-Colombia, AfroLatino, travel narrative, identity, racial descrimination.

\footnotetext{
* Color line, fault line: Piri Thomas and Manuel Zapata Olivella write the Jim Crow South.

${ }^{1} \mathrm{PhD}$ combined Spanish and Portuguese (Vanderbilt, 2014). Profesor Asistente de Español y Estudios Afro-Americanos en la Universidad de Alabama en Birmingham. e-mail: jtmaddox@UAB.edu
} 


\section{Introducción}

Down These Mean Streets (Por estas calles bravas, 1967) del "nuyorriqueño" Piri Thomas (1928-2011) es un clásico de la literatura afro-latina de los Estados Unidos. Fue un bestseller en los Estados Unidos desde el momento de su publicación, en gran parte por la influencia cultural de los movimientos a favor de los derechos civiles y el Black Power. ${ }^{2}$ Por otro lado, Manuel Zapata Olivella (19202004) es el novelista afrocolombiano más reconocido, aunque su obra apenas ha comenzado a recibir la atención internacional que merece, como es evidente en el homenaje internacional organizado por Mina Aragón, en 2014, y cuyas memorias aparecen en Un legado intercultural (2016). Cuando jóvenes, ambos autores dejaron atrás sus lugares de origen -Zapata en los años 1940 (Arbeláez, 2006) y Thomas pocos años antes de su arresto en 1950 (Thomas, 1967)- y partieron por voluntad propia rumbo al Sur de los Estados Unidos durante la época de las leyes de segregación racial llamadas Jim Crow. ${ }^{3}$ Es curioso que su destino haya sido ese, si tenemos en cuenta que aproximadamente seis millones de negros, casi la mitad de la población negra de la época, se fueron del Sur, entre 1915 y alrededor de 1970, en una de las migraciones más grandes de la historia del país (Wilkerson, 2010).

Según el Equal Justice Initiative, la Gran Migración, la que antes se consideraba resultado de las oportunidades económicas del Norte, era en realidad un éxodo del terrorismo racista. Muchos negros temían linchamientos (ahorcamientos públicos realizados en grupo, principalmente contra hombres negros, a manos de pandillas racistas como el Ku Klux Klan), que ocurrían fuera de las cortes del Sur. Era tan peligroso viajar por el país que se editaba un "Libro verde" de restaurantes y hoteles que servían a los negros (NYPL, 2017). Aunque la mayor concentración de negros de Estados Unidos se encuentra en el Sureste, por su historia esclavista, la presencia en el área no implica movilidad. Un buen ejemplo es el reportaje de Brown (2017) sobre el Negro Motorist Green-Book (1936 a 1964). Aunque Taylor afirma el peligro de viajar como negro en todo el país, las narrativas muestran que el Sur es, para los narradores, un lugar de peligro

\footnotetext{
${ }^{2}$ Cf. Roberts (1995), Hernández (1997), McGill (2002), Sánchez (2005), SantiagoDíaz y Rodríguez (2009). Dhouti (2007) compara a Zapata con Thomas.

${ }^{3}$ Uso los apellidos para los autores históricos/implícitos y los nombres de pila para los protagonistas de las obras. Los números de página vienen de la traducción de Tittler de Zapata y del texto original de Thomas.
} 
único. ${ }^{4}$ ¿Por qué querría un hombre de color viajar de la estabilidad relativa del Norte, comparativamente más racialmente "integrado", y de una Colombia que se decía "mestiza", sin segregación legal, a esta zona catastrófica de relaciones inter-racionales? ${ }^{5}$

4 Zapata habría podido observar la supremacía blanca en el Medioeste Norteamericano, pero lo habrían expresado en formas de origen sureño, como el KuKlux-Klan (establecido en Tennessee y renacido en Georgia), la bandera reconocida de la Confederación y las leyes segregacionistas de origen sureño modeladas sobre los Códigos Negros. Aun fuera del Sur, el racismo se asocia con él. Según Brown: "En esa época, agotar la gasolina del auto podría resultar en un encuentro con el Ku Klux Klan. Un desvío equivocado en un 'sundown town' (un pueblo del atardecer) -donde no se permitía que los afroamericanos salieran después del anochecerpodría resultar en un linchamiento. Algunos de estos pueblos hicieron letreros que avisaban 'Negro, no dejes que se te ponga el sol' ". "Era una cuestión de vida o muerte para los viajeros negros", afirma Candacy Taylor, estudiosa de Harvard. "Travel was dangerous in the South, but it was perilous in the rest of the country, too". "Segregation was still in full force, but there were fewer signs," said Taylor, who is retracing Green Book destinations and creating an interactive map. "There were lynchings still happening," including people beaten or tied to the bumper of a car and dragged out of town." (2017). ("Los viajes eran peligrosos en el Sur, pero era peligroso viajar por el resto del país también”. "La segregación racial todavía estaba en plena vigencia, pero había menos indicios", afirma Taylor, quien desanda los sitios anunciados en el "Libro verde" y creando un mapa interactivo. "Los linchamientos todavía estaban ocurriendo, incluso palizas de personas o amarrarlas al parachoques de un auto y rastrarlas fuera de la ciudad" (La traducción es mía).

${ }^{5}$ La geografía cultural contemporánea de los Estados Unidos se divide, en términos generales, en el Noreste, el Noroeste Pacífico, el Medio Oeste y el Suroeste, lo que se conoce más comúnmente como el Sur. Cada región tiene diferencias históricas y demográficas. Sin embargo, afirmar que el "Norte" y el "Sur" no existen implica que la Guerra Civil (1861-1865), un momento fundacional del país, no ocurrió. Esto se puede apreciar en los sinónimos de la guerra: La Guerra de Sucesión Sureña y la Guerra de Agresión Norteña. El presidente que lideró la invasión del Sur, Lincoln, era de lo que es hoy el Medio Oeste (Illinois) y Texas, el estado más grande del Suroeste. Era parte de la Confederación del Sur por sus afanes independentistas. La mezcla cultural de Texas y el Suroeste incluía a los mexicanos, además de los indígenas, población que también sufrió racismo en el Sur por su pasado colonial junto a los cautivos africanos y sus descendientes. Estos incluyen a la gente negra, tanto en términos fenotípicos como en términos genéticos. En todo caso, el supremacismo blanco en Estados Unidos siempre se ha dirigido hacia los no-blancos, independientemente de la población (negros, indígenas, asiáticos, chicanos), aunque en formas diferentes. Las leyes racistas del Sur se intensificaron durante la época de la Reconstrucción después de la Guerra Civil (1863-1877), en particular la "Redención Sureña" (1873-1877), en la que gobernantes del Sur rechazaron reformas antirracistas, entre otras, impuestas por el gobierno federal. Por esta guerra traumática y por haber sido el centro de la industria y el abolicionismo, el Norte (Noreste) siempre se ha visto como superior al Sur (Suroeste). Esta visión es complicada, desde luego, por la institucionalización de la segregación en todo el país a partir de 1896, con diferencias que dependían del gobierno de cada estado. La abyección del Sur ha creado el mito de que el racismo no existía en el Norte, un mito que Thomas y Zapata desmienten de maneras diferentes. 
Las respuestas a esta pregunta iluminarán cómo interpretamos la literatura (afro-)latina de los Estados Unidos y cómo analizamos la literatura afrocolombiana, continuando el diálogo entre dos tradiciones críticas sobre la discriminación racial y la identidad: la norteamericana y la colombiana, unidas por la afrodescendencia. También otorga reconocimiento merecido a Zapata por su relato de viaje, que, en vez de vender miles de libros como Thomas, quedó en el relativo anonimato hasta ser reeditado en el 2000. Valero (2013) argumenta que los críticos de la literatura afrocolombiana deben tener en cuenta los orígenes recientes (cerca del 2000), locales e internacionales, del concepto "afrodescendiente". Revisa así la historia de la crítica de las letras afrocolombianas, que, en sus orígenes, fue dominada por críticos afro-céntricos de los Estados Unidos (a partir de los años 1970), en inglés, desde sus propias ideas de blackness (2013). Valero busca más historicidad y pensamiento crítico en los estudios afrocolombianos para evitar la naturalización de las categorías etno-raciales de escritores y en sus obras. Wade (1995) confirma los argumentos de Valero acerca de que la historia de los conceptos de "negritud" y "afrodescendencia" en Colombia es única. Para Wade, el discurso de la "afro-colombianidad" hoy tiene menos que ver con la política de los Estados Unidos y más con las reformas legales con respecto a las tierras contenidas en la ley 70 de 1993. Por otro lado, el viaje de Zapata al Sur, en 1947, muestra su importancia como figura fundacional de la literatura afrocolombiana, porque ya en esa época la negritud no era para él sólo genética o folclor (como sí para la mayoría de los estudiosos colombianos de la época [Valero, 2013]), sino una política de identidad con fines de resistencia.

Zapata fue influenciado profundamente por los negros de los Estados Unidos y su viaje al Sur tiene paralelos con las memorias fundacionales de Thomas que cambiarían las identidades afroamericanas y latinas. La actualidad de la codificación de la Unesco de las identidades "afro" -la que une una diáspora dividida por nacionalismos- reafirma la importancia de los precursores Zapata y Thomas y sus experiencias comunes muestran la utilidad de una aproximación hemisférica y diaspórica a la literatura afrohispana. Las investigaciones más ricas de la afrodescendencia vendrán de una apreciación no sólo de factores locales, sino de factores globales e inter-americanos, sin caer en la homogenización de EE.UU y Latinoamérica. Decir que Zapata se identificaba con los afroamericanos no niega su marxismo ni su experiencia vivida como residente del barrio negro de Getsemaní, en Colombia, que también influenciaron su interpretación del discurso racial. Palacios (2015) muestra brillantemente cómo Zapata usó los discursos del folclor 
y el mestizaje triétnico (afro-indio-euro) de su momento político para apreciar las raíces negras de la nación colombiana y hacer visibles su marginalización e influencia cultural. Sin embargo, la "línea de color" de los Estados Unidos intensifica su solidaridad no sólo con la nación colombiana y Latinoamérica, sino también con la diáspora por toda América.

Podemos decir con Cohn (2007) que en los viajes de ambos autores la diáspora une los campos divididos de los Estudios del Sur (Norteamericano) y el Sur Global (Latinoamérica) en lo que denomina llama "Plantation America" y sus realidades poscoloniales, como la identidad del "U.S. Southern Black" (40, 43). Estos serían los guías para los dos protagonistas peregrinos. Aunque es norteamericano, no se puede afirmar que Piri conozca las normas de conducto del Sur mejor que Zapata. El movimiento de aquél se limita a los barrios de Nueva York -donde la segregación se impone en las calles por medio de pandillas étnicas, que evitan casi todas a la policía y las leyes oficiales- y tiene poco conocimiento de las normas y la violencia institucionalizada del Sur. Hay que buscar nuevas maneras de interpretar el impacto de la lucha por la identidad afirmativa y los derechos civiles de los negros en los Estados Unidos sobre Zapata y Thomas, y a mi forma de ver, el desastre es una manera útil de interpretar los conflictos inter-raciales en la prosa de ambos. En varias obras de Zapata, en particular He visto la noche, y en la primera autobiografía de Thomas, el Sur Norteamericano es como una falla geográfica entre las "placas tectónicas" culturales de América. El Sur es como el epicentro de un terremoto que revela las fallas del racismo y la xenofobia por toda América. Las normas, las leyes, el lenguaje y los linchamientos eran desastres que estos escritores querían reportar al resto del mundo. Eran traumas fundacionales para ambas identidades afro.

Mi base teórica para discutir una "(afro-)latinidad hemisférica" viene del libro Continental Shifts (2015) de Riofrío [sic]. El crítico se opone a los paradigmas que limitan la identidad latina (interpretada muchas veces por la crítica norteamericana como grupo minoritario, sin considerar la influencia continua de Latinoamérica) al territorio actual de los Estados Unidos. Los "latinos" no son un grupo homogéneo, sino grupos distintos que a veces forman un bloque latino en referencia a los Estados Unidos para fines políticos (2006). Sin embargo, para Riofrío y para mí, “[...] it doesn’t make sense to suppose that Latino identities 'begin' when one crosses the northern shore of the Rio Grande [...] [they] are thus simultaneously 
American and 'American' " (2015: 36) ${ }^{6}$. Con esto, Riofrío quiere decir "trans-" o "inter-americano" (38). Riofrío trata "las Américas" como si fueran placas tectónicas culturales y políticas que deslizan y chocan una contra la otra de formas varias a lo largo de los últimos treinta años (2015: 2). En este contexto, las identidades latinas suelen comenzar con un "sueño americano" que se basa tanto en el consumismo y la movilidad social como en las intervenciones políticas, militares, mediáticas y comerciales de Estados Unidos en Latinoamérica. Los textos de Zapata y Thomas muestran otro tipo de choque intercultural debido al contexto de la segregación racial y las identidades racializadas. ${ }^{7}$

\section{Los ideales de la solidaridad colectiva eran diferentes del neoliberalismo pos-NAFTA de los años 1940 y 1950. Stavans}

\footnotetext{
6 "No tiene sentido suponer que las identidades latinas 'comienzan' cuando uno cruza la orilla norteña del Río Grande [Bravo] [...] así [los latinos] son simultáneamente americanos y 'Americans' [estadounidenses]. (La traducción es mía).

${ }^{7}$ El campo que más ha tratado la obra de Thomas corresponde a los estudios latinos de los Estados Unidos, a veces llamados "Latinxs" para referirse a la minoría étnica de ese país y no los residentes de Latinoamérica. Una voz nueva y relevante en este campo es Riofrío, hijo de inmigrantes ecuatorianos, quien enseña en la Universidad de William and Mary. Riofrío propone una "Latinidad" (identidad latina asociada con EE. UU) que es "hemisférica", trascendiendo las fronteras nacionales de América (2015: 9). Arguye que los medios de comunicación norteamericanos han deshumanizado a los latinos desde la explosión de inmigración hispana a los Estados Unidos, desde la aprobación del Tratado de Libre Comercio del Norte en 1993: una exclusión política que se intensificó después de los ataques terroristas del once de septiembre de 2001. "Por eso, mi título pretende invocar una base teórica que interpreta los dos hemisferios [los del norte y del sur] como más íntimamente interconectados en términos demográficos, culturales e ideológicos" (Riofrio, 2015: 12. La traducción mía). Es más, su interpretación de la identidad latina tiene en cuenta el discurso racial sociológico. Su aproximación es útil para este artículo porque muestra claramente la fluidez entre la literatura latinoamericana y la de los latinos de Norteamérica. Riofrío busca evitar la homogenización racial de los latinos, pero no analiza la obra de los afro-latinos como Zapata y Thomas e ignora el Caribe en general. El autor concede, sin embargo, que muchos de los choques culturales entre Latinoamérica y Estados Unidos a causa de la inmigración comienzan en los años 1960. Trata el racismo como un mal hemisférico: "el supremacismo blanco único de inclusión y exclusión que subyace las estructuras de los Estados Unidos, aunque raras veces se reconoce, reaparece de vez en cuando [...] el huracán Katrina, y en particular en la película sobre Katrina de Spike Lee, When the Levees Broke 'Cuando los diques rompieron', destaca la extensión de esta exclusión [...] El resultado fue clamor público y una preocupación intensificada con la idea de que, de repente, como consecuencia directa de Katrina, los Estados Unidos se parecía con un país del Tercer Mundo" (19). En los textos de Zapata y Thomas, vemos una inversión del excepcionalismo estadounidense que es la raíz de este asombro: la idea de una región de los Estados Unidos como una zona afectada por un desastre hemisférico; la supremacía blanca, vista por viajeros que tienen puntos de vista particulares como afro-latinos. Mi aproximación hemisférica complementa la de Rivera-Rideau, Jones y Paschel (2016).
} 
ubica a Thomas en la época de "Turbulencia" de la literatura latina (1946-1974), cuando las identidades anti-asimilacionistas de los nuyorriqueños, los afro-latinos y otras identidades se formaban y su aproximación inter-americana debía haber incluido a Zapata (2010, p. 584). Leer a Thomas y a Zapata juntos puede interpretarse como recuperar precursores de los escritores latinos en el espíritu del Recovering the US Hispanic Literary Heritage Project (Proyecto de recuperación de la herencia literaria norteamericana) de Kanellos. Dalleo y Machado Sáez notan el impacto fuerte de los movimientos a favor de los derechos civiles sobre los escritores de los años 1960 (2007). Aunque los viajes de Zapata y Thomas tienen lugar durante los años 1940, sus textos se publicaron o se re-editaron en los años $1960 .{ }^{8}$ Las luchas de esta época por la justicia influenciarían profundamente cómo los críticos norteamericanos evaluaban si una obra era política o no , aunque Dalleo y Machado Sáez han matizado estas interpretaciones en la época neo-liberal (2007). La metáfora del "movimiento continental" de Riofrío, un choque socio-político de las culturas americanas a través de varias fallas geográficas, todavía es una aproximación apropiada a estos textos de la época de Jim Crow. Ya que ambos autores vivían en la época de la segregación oficial en el Sur Norteamericano, su equivalente al "sueño americano" que los inspira a aventurarse en la tierra del K.K.K. era más bien una pesadilla. Sus identidades afrolatinas respectivas les dieron ganas de conocer lo que estaba pasando allá de verdad.

Los escritores afro-latinos/hispanos como Zapata y Thomas son, para Luis (2012), los que tienen identidades profundamente influenciadas por la estratificación racial latinoamericana -el Caribe en particular, en los casos de estos autores- y de los Estados Unidos (34). ${ }^{9}$ Esta desigualdad se radica en la historia de la esclavitud y el racismo en Colombia y Puerto Rico. Omi y Winant (1986) llaman a este fenómeno "formación racial" (61). No obstante, no había

\footnotetext{
${ }^{8}$ Pasión salió en 1949 y He visto, en 1952. Este último fue reeditado en 1969 con el subtítulo Raíces de la furia negra. Streets salió en 1967. Esto afirma la observación de Dhouti (2007) sobre el impacto del movimiento de los derechos civiles sobre Thomas. Martínez-San Miguel (2014) nota que la publicación de la novela en 1967 ocurrió sólo un par de años después de la declaración de la Ley Estadounidense de los Derechos Civiles y de Votación.

${ }^{9}$ Luis (1997) considera "Hispanics" [sic] a los que se identifican con Hispanoamérica y "Latinos" [sic] a los que se identifican con el Estados Unidos anglófono (34). Oboler (1995) considera "Hispanic" [sic] una identidad impuesta por el gobierno estadounidense sobre una identidad "latina" definida por la comunidad misma (7). Sánchez y Pita (2007) se refieren a un bloque latino que evita homogeneizar estas poblaciones diversas. Uso aquí "latino" de la misma manera que Sánchez y Pita y Riofrío (2015). Luis, sin embargo, estudia a los afro-latinos, a los que Riofrío deja fuera de su libro.
} 
segregación al estilo Jim Crow o la llamada "one-drop rule" (norma racial de una sola gota en la que una "gota de sangre", o ancestro, es africano, haciendo al descendiente "negro", independientemente de su fenotipo). ${ }^{10}$ Latinoamérica suele acudir al fenotipo para determinar la "raza" [sic], que es en sí un constructo social, político y cultural radicado en la esclavitud y el colonialismo (Rodríguez, 2000: 107). Los hijos pueden nacer con realidades muy diferentes dependiendo de su color y sus rasgos físicos.

\section{La descendencia familiar de los autores-protagonistas}

En términos de familia y clase social, los dos autores-protagonistas tienen orígenes muy diferentes. Zapata era hijo de Antonio María Zapata Vásquez, un profesor descendiente de africanos y Edelmira Olivella, una madre mestiza de descendencia catalana y zenú (Zapata, 1990: 33 y 41). Vivían en el pueblo de Lorica, cerca de Cartagena de Indias, antes de trasladarse a Getsemaní, un barrio de población mayoritariamente afro y de clase trabajadora. Manuel era afro-latino y acogía su identidad negra desde su juventud en Getsemaní (1990: 118; Dhouti Martínez, 2007: 134), aunque dijo en una entrevista que le gustaba más la flexibilidad de una identidad "mestiza" (Krakusin, 2001: 15). Manuel, sin embargo, tenía piel oscura y pelo crespo: un fenotipo negro. Es más, el padre de Manuel siempre afirma su descendencia africana (1990). Por otro lado, el positivista letrado Antonio funda el colegio "La Fraternidad" donde enseñó a sus hijos y los crió como grandes lectores de ciencia y literatura, algo poco común para costeños negros en este contexto (Zapata, 1990: 92). Quiere tan vehementemente que sus hijos salgan de Getsemaní a través de la educación que destruye su propio salón de clase cuando el hermano de Manuel, Virgilio, decide no continuar sus estudios. El padre de Manuel lo registra para la escuela médica en Bogotá a la fuerza. Es uno de dos estudiantes negros en su clase, así que uno puede ver su hiato de una escuela de medicina casi totalmente blanca que sirve a la élite como una búsqueda por un nuevo contacto con el pueblo humilde de América. Aunque Zapata considera a su padre un liberal académico, Manuel intenta formar un lazo directo con los oprimidos. A pesar de sus diferencias con su padre, su escena de despedida es conmovedora -su sabático de la universidad enfurece a Antonio, pero Edelma mantiene la familia unida para que, algún día, su hijo pueda regresar (1990: 214). Su salida es diferente de la de Piri, que éste llama un "funeral" (1967: 149) para su niñez turbulenta (Cruz-Malavé, 2012: 15).

${ }^{10}$ Davis (5-6). 
En términos económicos, los viajes al Sur Norteamericano igualan a los dos protagonistas. Zapata afirma que su viaje fue inspirado por una combinación de pasión vagabunda y una búsqueda por entender las necesidades de los marginados y continúa su activismo previo. Ya había organizado un "Día del Negro" en la Universidad Nacional (1990: 187). El médico marxista Alfonso Uribe Uribe le enseñó allí sobre las raíces políticas de las enfermedades, inspirándolo a conocer mejor a los oprimidos. Zapata casi no tenía dinero durante su peregrinación, lo que lo distingue de los viajantes clásicos de la literatura latinoamericana, como Sarmiento (Branche, 2008: 223). A diferencia de Zapta, Piri es marginalizado desde el principio en términos raciales, étnicos, educativos y de clase. Su narrativa comunica más resentimiento que superación, un punto de vista comprensible para un exprisionero que está retratando su marginalización y encarcelamiento. Jiménez Román y Flores (2010) consideran la autobiografía de Thomas "nada menos que una anatomía sicológica de la paradoja afrolatina y la lucha tormentosa de afirmar las dos identidades" (209-210) -es discriminado por ser pobre, negro y latino-. Mientras Manuel lee sobre el Renacimiento Negro de Harlem en Latinoamérica, Piri vive en "home, sweet Harlem" (mi casa en las calles de Harlem). Allí pelea con pandillas étnicas blancas y acaba abandonando el colegio. Se muda con su madre a las afueras blancas de Long Island en su adolescencia, pero se siente alienado en cuaquier lugar, con la excepción de Harlem del Este (Spanish Harlem).

La marginalización de Piri también es familiar. El narradorprotagonista afirma que su propia familia trata mejor a sus hermanos, los que tienen narices afiladas y pelo liso que a él por su tez oscura y nariz africana. ${ }^{11}$ Si la familia niega esta discriminación en casa, el padre obrero y poco instruido de Piri niega el racismo en el mercado laboral del Norte. Para Piri, su padre es víctima de

${ }^{11}$ La casa es la metáfora latinoamericana más común para la nación -una "gran familia", como señalan Santiago-Díaz y Rodríguez (2009: 1206), así que salir de casa es dejar atrás una identificación mestiza no-negra, la que predomina en Puerto Rico y entre la familia Thomas. Por eso, la novela es un bildungsroman o novela de aprendizaje (Caminero-Santangelo, 2007; Cruz-Malavé, 2012: 7). Según Dhouti (2007), al ir al Sur, Piri se legitima en sus ojos y los de Brew por testimoniar el racismo explícito y por eso adoptar una identidad negra (69). Pero también es para demostrarle algo a su padre. Martínez-San Miguel (2014) alega que Piri es invisible para su padre (122). Cruz-Malavé (2012: 7) propone que el niño busca un modelo racial/étnico en su padre que no encuentra. Como señala Cruz-Malavé, entrar en "alien turf" (tierra extranjera) de niño le hace sentir más hombre, pero el crítico no nota el viaje que le convence a Piri que ya no es niño (1997: 335). Di Iorio Sandín (2004) diagnostica a la familia con "racial melancholia" (melancolía racial) (103-116). El viaje lleva al "descubrimiento de su negritud”, lo que nota MartínezSanmiguel (2014), pero ella ignora la importante zona fronteriza del Sur (122). 
un sistema racista que no permite que un negro "extranjero" avance más allá del peldaño más bajo de la jerarquía social, a pesar de su ciudadanía estadounidense (153). ${ }^{12}$ Trabaja incesantemente haciendo tareas manuales y luchando para no perder el empleo. No obstante, niega repetidamente que la discriminación racial sea un factor en su situación. El inmigrante reciente se ve como mestizo y totalmente diferente de los negros. Piri se despide de su familia inmediatamente después de una pelea a golpes con su hermano José, una erupción de resentimiento hacia el racismo. Cruz-Malavé (2012) considera este momento el clímax de la novela que nadie nota: la confesión explosiva del racismo de la familia Thomas. La pelea es parte de su salida hacia el Sur: un testimonio de los desastres de la segregación norteamericana y el racismo radicado en la esclavitud de Latinoamérica.

La confrontación con el Sur representa una recuperación de la masculinidad para Piri, la que su padre afro-latino siente que ha perdido en el mercado laboral buscando un "sueño americano" que se le ha negado debido al racismo (1967: 119). La segregación en Nueva York se imponía en el trabajo por la discriminación tácita y en las calles por medio de pandillas, que evitaban casi todas a la policía y las leyes oficiales; pero Piri tenía poca idea de cómo eran las normas y la violencia institucionalizada en el Sur mientras vivía en Harlem. Por eso hace falta el guía-mensajero afroamericano Brew para orientar a Piri. En esto se asemeja a Manuel, que se informa sobre el Sur en el Norte y el Oeste, antes de enfrentar la zona de peligro. En este sentido, los dos tienen orientaciones similares, aunque con lagunas que quieren mejorar a través de sus viajes. Es más, sus reacciones frente a las injusticias del Sur no siempre resultan de su ignorancia frente a las normas opresivas, sino a la rabia que sienten por ellas. Para los dos protagonistas, ir a la "zona afectada" es una manera de salir de casa con todas sus tensiones e infantilización y "hacerse hombre" independientemente. Los papeles de estos hombres en la "zona afectada" del Sur son distintos. Piri alega ser un testigo curioso en busca de saber "what's shaking" (¿qué pasa?) (158). No obstante, no se contenta con sólo mirar y se lanza al conflicto (Medina-Rivera, 2003). Por otro lado, Zapata llega al Sur habiendo viajado por otras regiones y desempeña el papel

\footnotetext{
${ }^{12}$ El padre de Thomas era cubano, pero es puertorriqueño en el libro (MartínezSan Miguel, 2014: 106). Luis (2006) alega que muchos cubanos sólo comienzan a verse como afrocubanos al entrar en contacto con afro-americanos y afro-boricuas (148), un origen híbrido de identidad afro-latina. Cruz-Malavé (1997: 331) enlaza a la familia con la ciudadanía. En el caso histórico de Thomas, la no-ciudadanía de su padre puede haberle afectado de manera negativa en el trabajo, aunque la ciudadanía oficial puertorriqueña no parece ayudar mucho al padre de la narrativa.
} 
de un reportero, por lo que hace su testimonio más formal que el testimonio crudo de Thomas.

\section{Los textos viajeros}

Uno puede interpretar el sentido renovado de justicia social de Piri y Manuel hacia los negros como una "remesa cultural" del epicentro de la segregación. Riofrío (2015) se apropia de este término de Flores que usa la metáfora neo-liberal de las "remesas: mercancías o fondos que los latinos envían a los países de origen de sus familias (39). Flores (2009) considera "remesas" también las ideas e identidades, y cuando los "remigrantes" vuelven a Latinoamérica estas "remesas" alteran a los demás (41). El viaje de Zapata desde Sudamérica hasta el Sur norteamericano resultó en un artículo periodístico y un diario de viaje, y tendrá ramificaciones a lo largo de su carrera. La "remesa" de Thomas no se remite a Puerto Rico, sino al público lector norteamericano, ya que su obra creó nueva consciencia de los boricuas dentro del territorio continental, los afro-puertorriqueños en particular (Luis, 1997). Es más, Santiago-Díaz y Rodríguez (2009) muestran que lo que llamo "remesa" de encarar el racismo también se remite a su familia y al autor mismo. Es una ruptura con la ideología de la "Gran familia puertorriqueña" que vivía en armonía y la adaptación de una "ideología racial afrohispana [sic]" (2009: 1210). Viajar por el Sur, región que Santiago-Díaz y Rodríguez (2009) consideran una "frontera", cambia a Thomas:

El peregrinaje por los estados del sur ciertamente aumentará el sentido de solidaridad de Piri con los afro-americanos en contra de la supremacía blanca; pero a la vez, reforzará su resistencia al binarismo en blanco y negro que oblitera otros elementos distintivos de su identidad. A su retorno al Harlem hispano, el héroe continuará afirmando su diferencia lingüística y cultural, y aun al final del tránsito vital su dilema todavía se mantendrá irresuelto (1211).

Aunque el afro-boricua no crea una identidad negra o latina homogénea, fortifica su solidaridad con los afro-americanos en la lucha contra la discriminación. De la misma manera, Zapata ganó solidaridad con los afro-americanos, aunque tampoco buscaba una identidad homogénea. Mientras estudiaba Medicina en Bogotá, se embarcó en una peregrinación por Centroamérica, hasta México, y de allí siguió a Estados Unidos, donde se quedó de 1943 (Zapata, 1990) a 1947 (Prescott, 2007). Estos viajes se retratan en sus 
autobiografías Pasión vagabunda $(1949,2000)$ y He visto la noche (1953, 2000), y el autor reflexiona sobre ellos en ;Levántate mulato! Por mi raza hablará el espíritu (1990). Influencian el drama Hotel de vagabundos (1955), el cuento “Un extraño bajo mi piel” (1967), la novela experimental Changó, el gran putas (1983, 2010), y aun varios ejemplos de su obra ensayística. Las escenas de estas obras publicadas, además del artículo recién redescubierto que el autor probablemente escribió para la revista mexicana Mañana (Zapata, 2000: 242) tienen lugar en el Sur norteamericano.

Durante su primera incursión al Sur, Manuel es corresponsal en una zona afectada. Esto no quiere decir que su testimonio sea "objetivo", ya que agregó el subtítulo "Las raíces de la furia negra" a la edición de 1969 de He visto la noche (Olliz, 1992: 113). Su rabia es colectiva y reflexiva, ya que altera el tono del título de la versión de 1953, quizá teniendo en cuenta el hecho de que los latinoamericanos podían ver las luchas en Birmingham (1963), Selma (1965) y otras ciudades sureñas en sus televisiones, como afirma Garland Mahler (2015). La política de Jim Crow era infame por toda América Latina (Tillis, 2005: 32). Prescott (2007) retrata el horror de los viajeros latinoamericanos frente al linchamiento y las leyes de Jim Crow desde el fin del siglo XIX hasta el viaje de Zapata. La segregación racial era tan restrictiva que dio credibilidad a la "Cuba sin razas [sic]" de Martí en Nuestra América (Prescott, 2007), la "raza cósmica [sic]" de Vasconcelos, la "transculturación" de Ortiz y la "democracia racial" de Freyre, todas teorías que, a pesar de sus metas y contextos diferentes, retrataban a Latinoamérica como el opuesto armonioso del Estados Unidos racista. Mientas su viaje por Centroamérica y México influencia su Weltanschauung, Zapata presenta su supervivencia a Jim Crow como su inspiración a regresar a Colombia y ejercer la medicina entre los pobres (2007) y dedica He visto la noche a la experiencia, dando al Sur un lugar especial en su obra.

Cuando Manuel está en Centroamérica y México, se interpreta su identidad como mestizo. Esto quiere decir que, cuando entra en la Ciudad de México, los campesinos desamparados allí creen que él es un sobrino del revolucionario Emiliano Zapata (Zapata, 1990). La misma lógica, basada en los fenotipos, informa su afirmación de que modeló para Diego Rivera y que se incluye entre el pueblo retratado en un mural de la Secretaría de Educación (1990). Es imposible saber si cualquiera de estas historias es verdadera, pero su narración indica que Manuel tenía identidades mestizas y hasta indias en Latinoamérica, ya que Rivera lo retrata como olmeca (1990). Manuel vive de trabajillos durante sus viajes, incluso uno como periodista que lo lleva a cruzar la frontera estadounidense al 
lado de los braceros mexicanos (1990), la fuerza laboral que trabajó en los campos norteamericanos de 1942 a 1964, en un programa que comenzó cuando muchos hombres estadounidenses estaban luchando contra Hitler (Stavans, 2010).

Cuando Manuel cruza la frontera en Ciudad Juárez-El Paso, entra en la realidad política de la línea de color (Zapata, 2007). No pasa mucho tiempo en Texas, pero es cuando comienza a identificarse con otros latinos y verse a sí mismo como tal al lado de los braceros, a quienes llega a representar como portavoz y negociador. Aunque nunca usa el término "latino", su marginalidad crea una unidad que él llama "pan-americana" (185). Uno debe tener en cuenta que el viaje de Manuel durante los años 1940 ocurre mientras que la categoría "Latinoamérica" está siendo popularizada por primera vez en el Primer Mundo (Bethell, 2010: 474). Una identidad "Latina" común en Estados Unidos era parte de una identidad "pan-americana" que crea una coalición distinta de la cultura hegemónica de los Estados Unidos y no el pan-americanismo diplomático de la época que servía para fines imperialistas norteamericanos (Zapata, 2007: 185).

Desde la frontera de Texas, Manuel viaja a Los Ángeles, donde lo tratan diferentemente en el lugar de trabajo por ser afro-latino. No encuentra el "sueño americano" de la movilidad social (de hecho es su marginalización lo que respalda su solidaridad negra). Siendo un estudiante de medicina en sus últimos años de estudio, el joven acepta, inocentemente, trabajar como asistente médico en el Hospital General de Los Ángeles. Le dan una escoba y lo mandan a limpiar. Un día, Zapata le corrige públicamente a un doctor durante un discurso y su única recompensa es un día de limpieza de bacinillas. Después de convertirse en héroe entre los negros del hospital, Manuel sale para Chicago, asqueado. Por su solidaridad con los negros, cuando el joven padece de hambre en Illinois, es el carismático y caritativo Father Divine el que le da comida y lo invita a su iglesia al lado de otros refugiados de Jim Crow. Por la solidaridad negra, Manuel viaja a Harlem e, intrépidamente, toca la puerta de su héroe literario, Langston Hughes, y le pregunta si pueden discutir su obra. Sorprendentemente, Hughes lo invita a entrar y lo hospeda por días hasta que su pasión vagabunda lo manda al Sur. Aunque Flórez Bolívar (2015: 112) ha mostrado que Harlem es la "cuna" de la negritud para Zapata, el Sur es donde Zapata se convierte en hombre.

Piri tiene que ir al Sur en busca de algo inexplicable, sintiendo "like being hung up between two sticks" ['como estar colgado entre dos palos'] (1967: 119). Hay una alusión probable a los ahorcamientos 
por pandillas de blancos en esta metáfora. Cuando Piri decide salir, le pregunta a su amigo afroamericano Brewster Jackson: "What, a cat's gotta be hung before he knows what's happenin'? ['¿Y qué, un tipo tiene que ser ahorcado para entender?']" (1967: 126). Antes, Piri confiesa,

True, I ain't never been down South, but the same crap's
happening up here. So they don't hang you by your
neck. But they slip an invisible rope around your balls
and hang you with nice smiles and if we need you, we'll
call you. ["Es verdad, nunca he estado en el Sur, pero la
misma mierda está pasando acá. O sea, no te cuelgan
por el cuello, pero te deslizan una soga invisible por
los huevos y te ahorcan con sonrisas gentiles y "si lo
necesitamos, lo llamaremos"] (1967: 124).

Brew habla como si "down thar" ['por allá'] (el Sur) fuera más "real", porque es más doloroso, radicando su esencialismo inconsciente en la violencia y, diría yo, el peligro (Cruz-Malavé, 2012, p. 13). Para Cruz-Malavé (1997), Piri ve en los afro-americanos sureños un espíritu de lucha frente a la segregación de una manera que era impensable para los antillanos hispanos (334). Cuando Piri viaja al Sur, tiene dos guías: un mexicano-americano y un afo-americano. Conoce a su guía mexicano-americano en un bar en Texas. Comparten los lazos del spanglish y la búsqueda de prostitutas. Las identidades afro y latino son evidentes en un diálogo intercontinental que ocurre después del coito entre él y una prostituta que pensaba que era un extranjero no-negro: "I just want you to know that you just got fucked by a [...] nigger, a black man!" (1967, p. 189) ("Quiero que sepas que te acaba de coger un [...] nigger, jun hombre negro!"). Su grito de triunfo, una explosión volcánica de angustia subterránea, indica la fuente de sus frustraciones mientras que se cría en Nueva York. Martínez-San Miguel (2014) ve en este episodio como un "estadio del espejo" en que se reconoce a sí mismo como negro e hispano por primera vez (120). Sánchez (2005) y Caminero-Santangelo (2007) ven esta erupción como un desahogo irónicamente racista para frustraciones raciales. Usando la teoría de Riofrío, podemos leerlo como un movimiento continental que involucra muchas formas de opresión -el racismo, el sexismo, el nacionalismo norteamericano- que chocan entre sí sin exonerar a Piri. Evidentemente, el enlace con mexicanos y extranjeros es central en su articulación como afro-latino, una identidad que desborda la "línea de color" y las fronteras americanas. 
En otros contextos del Sur, Piri entra heroicamente en las zonas de las catástrofes racistas. Su modo de transporte es un sitio que altera su identidad, tal y como lo es para Manuel. Al embarcar en el puerto sureño de Norfolk, Virginia, encuentra a un marinero blanco que lo llama "boy" 'niño' -un insulto común para hombres negros- y exige que le traiga café (1967: 183). Pero el nuevo Piri concientizado le avisa, como a la prostituta, que él es un "real chévere man" ['un hombre bien chévere'] (184). Durante su Odisea, Brew y Piri van a un restaurante en Mobile, Alabama. Los clientes blancos le dan miradas asesinas a Piri cuando éste se sienta para comer en el área de los blancos. Piri les devuelve la mirada. Grita groserías en spanglish puertorriqueño a un público de anglos, afirmando su identidad afro-latina por medio del lenguaje. Para CamineroSantangelo (2007: 66), Piri está agarrado a su "previlegio racial" puertorriqueño en esta escena. Por otro lado, al cruzar la "línea de color", está haciendo su propia protesta personal y anticipa los sitins (manifestaciones pacíficas) del Movimiento por los Derechos Civiles (su narración selectiva en 1967 probablemente alteró estos recuerdos de los años 40).

Otro argumento contra ver el "privilegio puertorriqueño" en esta escena es una anécdota de su viaje hacia el Sur que el autor contó después de publicar sus memorias. Stavans (2010: 584) incluye una entrevista con Thomas que alega que viajó al Sur en autobús y no en barco. A él y a su amigo "Billy" (y no "Brew") les pidieron que fueran a la parte de atrás del ómnibus con los demás negros al cruzar la "línea Mason-Dixon" que divide el Norte del Sur de los Estados Unidos. Cuando el nuevo chofer sureño lo llamó "colored" ['hombre de color'], Thomas respondió que era "puertorriqueño". El chofer contestó: "I don't care what kind of nigger [sic] you are" ["No me importa qué tipo de negro seas"] (Stavans, 2010: 584). No sólo sabía Piri Thomas, personaje ficticio o autor histórico, que no podía evitar el racismo al llegar a Mobile, sino también que ese momento fundacional en el autobús sería algo que jamás olvidaría.

En Mobile, Brew, a la espera de Piri, se da cuenta de que éste se ha puesto en peligro muy grave. Lo rescata y lo lleva de vuelta al barco. Brew está perturbado por el incidente y desaparece en el próximo puerto, Nueva Orleans. El afroamericano tiene por qué preocuparse. Quizá su pasado acaba alcanzándolo y se convierte en otra víctima de los desastres del Sur. De niño, antes de escaparse a Harlem, patea y golpea a un grupo de alabamianos blancos que quieren violarlo. Al vengarse violentamente, Brew recobra su orgullo como hombre negro que puede defenderse. También es el final de su fe en la noviolencia cuando enfrenta los ataques racistas. Se siente emasculado 
al punto de que Piri dice que ha "lost his cherry ['perdido su himen']" (1967: 162). Ir a la zona de desastre es una manera de rescatar su hombría percibida, con todo su machismo problemático. Su vuelta al Sur puede haber sido un error fatal, pero el lector no lo sabrá nunca. Lo que queda claro es que algo le atrae a regresar al peligro del Sur, quizá para superar el trauma o para proteger a su amigo. Piri se identifica con la furia, el resentimiento y el deseo de venganza por Brew durante su viaje.

Aunque Brew es un personaje ficticio, probablemente está basado, en parte, en el escritor afro-americano John Killens, quien invitó a Thomas a ser el primer puertorriqueño en el Harlem Writer's Guild (Gremio de Escritores de Harlem), que era sólo para negros (McGill, 2002: 180). En una entrevista, Thomas dijo que se hizo escritor como un acto de catarsis por la rabia que sintió al ser encarcelado. Cuando fue puesto en libertad, en 1957, Killens le dijo: "keep wailing, bro, keep wailing ['sigue wailing, hermano')” (McGill, 2002: 180). "Wailing" puede significar "tocar un instrumento", pero también significa "llorar" y "golpear". O sea, la sublimación del coraje: "I learned that words could be bullets or butterflies ['Aprendí que las palabras podían ser balas o mariposas']" (181). Las palabras pueden rescatar a los escritores y a los demás. Ayudar a huir del peligro.

El autor define su oficio en términos de la veracidad: "I wanted the readers of the book to feel the realness of what it was about ['Quería que los lectores sintieran la realidad del tema']" (Ibíd.). Thomas (1967) subraya la 'realidad' de la discriminación cuando describe el viaje de Piri a las Antillas, al salir de Galveston, Texas, en un performance de la esclavitud: trabaja echando carbón al horno de un barco para pagar la travesía (189). Es como si estuviera retratando las entrañas de la tierra, atestiguando las "fallas geográficas" de las Américas temblantes justo antes de que explotara la época de las luchas por los derechos civiles. Luego Piri se va al norte, habiendo descubierto su identidad afro-latina. Al ir al Sur, Brew y Piri están repitiendo la peregrinación de muchos escritores negros que cruzan la línea Mason-Dixon y entran en "an obligatory site of cultural sojourn ['un sitio de estancia obligatoria']" (Griffith, 1995: 146) que luego denuncian al regresar al Norte, o en el caso de Zapata (2000: 404), a Latinoamérica.

Yendo al Sur por tierra, como en la entrevista de Thomas, Manuel llama al ómnibus de la famosa compañía Greyhound la "Línea Negra", y se identifica con los pasajeros afroamericanos allí. Prescott (2007) y Orozco (2012) notan la importancia del bus en la visión que Zapata tiene de los Estados Unidos. Al igual que su 
experiencia en Texas, el narrador-protagonista nota la "línea de color" explícitamente (Prescott, 4), pero parece estar igualmente asombrado por la falta general de gente blanca en los ómnibus interestatales, ya que los blancos tenían más acceso a los automóviles personales. Orozco señala el hecho de que, mientras Manuel está en el autobús, tiene tiempo para pasar formando relaciones, principalmente, a través de conversaciones con los negros de las clases bajas. En Montgomery, Alabama, un pelotón de soldados sube al bus y Manuel forma amistades con los negros en la parte trasera del autobús. Manuel los invita a Sudamérica y sólo se despide de ellos al bajar en Mississippi, mostrando que se identifica más con ellos que con los blancos que ignoran a todos los demás. Como en el viaje de Piri, el descanso de Manuel en Mississippi se convierte en lucha cuando un mesero le niega comida al afro-colombiano, a lo que responde: "algún día los negros y los latinos le enseñarán a usted la decencia humana" (2000: 400), como analiza Prescott (4). Mientras Manuel es más elocuente que Piri, comparte con él la rabia y el deseo por un cambio radical en el Sur. Esto quedará claro en el texto "Un colombiano en la tierra del Ku Klux Klan", que no ha sido analizado aún por la crítica. Manuel testimonia el desastre como corresponsal oficial en ese artículo escrito para publicación entre 1946 y 1947 . Aunque no ha sido dado a la imprenta, está hoy en los archivos de Vanderbilt University, en Tennessee.

En el reportaje el afrocolombiano, que comienza el último tramo de su viaje en Harlem, aprende de sus vecinos afro que "todavía no han visto" el racismo porque los negros norteños viven en un "paraíso" (n.d., p. 1). Su reportaje comienza con imágenes chocantes. Mientras Manuel está en Atlanta, Georgia, le envían una invitación a una manifestación del Klan, en Stone Mountain (n.d.), quizá como un acto de terrorismo o un simple error. De alguna manera se esconde entre los congregantes, aunque su piel morena llamaría la atención de los presentes, y describe en detalle los mil racistas que llevan mantos blancos y queman una cruz gigantesca hecha de cajas de madera delante de diez mil espectadores. Estas imágenes habrían sido grotescas y novedosas para su público mexicano. Claramente, este infierno racista no es el paraíso que sus amigos negros del norte dicen que habitan.

Cuando sale de Nueva York en Greyhound, Manuel para en Washington por una noche. Hay una diferencia palpable entre cómo reflexiona sobre el memorial de Lincoln y sobre los restaurantes y hoteles que le niegan servicio durante su estancia. Por ser negro, en la capital del supuesto "defensor de la democracia" el reportero tiene que dormir solo, con frío y sin comer. Como Piri, Manuel se 
escapa por poco de los golpes de los racistas cuando se sienta a cenar en el área blanca de un restaurante. Alega que el único lugar donde podía hablar libremente era entre los negros que conoce durante su vagabundeo. El autor muestra que sabía que estaba rompiendo tabúes, ya que escribió bajo el pseudónimo "Manuel Karabalí" (n.d., p.1). Este reportaje se reproduciría y extendería en He visto la noche $(1953,2000)$. Manuel recibe el apoyo financiero de una organización mexicana anónima que lo obliga a publicar sus descubiertos en México (2000).

Un créole mulato de Louisiana y un estudiante de química le alertan que no debe ir al Sur porque temen que lo ahorquen. Miguel sigue adelante para "consagrar mi vida a combatir la iniquidad humana" después de enterarse de asesinatos del K.K.K en Monroe, Georgia, y de los linchamientos por todo el Sur. El autor alega que el Sur se convirtió en su "norte", que otorgó propósito a su deambulación por América, una "la lucha por redimir al hombre oprimido [...] vejado por el color de su piel [...]" (2000: 373). Cuando el Greyhound para en Richmond, Virginia, se le niega servicio de nuevo y se topa con una mujer negra de ropa elegante de fuera de la ciudad, que no puede dar de comer a su propio hijo porque no encuentra restaurantes para negros (2000). Manuel señala la injusticia de la discriminación racial por comparar al niño sano pero con hambre a la discriminación de clase en áreas pobres de Guatemala y Colombia (2000).

Manuel descubre desastres y heroísmo por todo el Sur. En Winston-Salem, conoce a Marta, que es líder sindicalista en la tabaquera Camel. Ella organiza sindicatos negros, lo que le inspira al reportero a rebelarse a favor del oprimido. Zapata nota cómo la lucha une a los trabajadores blancos con los negros en el Sur segregado. En Atlanta, visita un área negra llena de polvo de carbón y le da limosna a un hombre viejo sin piernas. El hospital negro no tiene medicina sino literas pestilentes. Las imágenes de un hombre sin piernas y el humo que sale de edificios decrépitos son como las de una zona de desastre. En Nueva Orleans, conoce a una pareja interracial que no puede vivir junta debido a la vivienda segregada y por eso piensan irse a Chicago. Joe, el esposo, se pone furioso porque ha luchado en una guerra y ha perdido a su hermano en Europa peleando contra los nazis y luego descubre que la supremacía blanca reina en su propio país. "La batalla continúa, sólo que hemos cambiado de frente" (2000: 395). La conversación con Joe inspira a Manuel a "combatir" el racismo y dejar de ser un "observador imparcial" (395). 
Mientras el desastre del racismo explícito afecta la identidad de Manuel, se le recuerda también al final de su viaje su identidad latina. El afrocolombiano forma enlaces con el chofer "mexicano"(americano), el que dice que sufre discriminación también, y conoce a chicanos (tejanos) que no pueden comer en restaurantes para blancos. Lo acompaña a buscar comida en los barrios negros, formando una amistad basada en solidaridad latina. Al final, el viaje de Manuel se completa al regresar a El Paso, Texas, y recuerda su miedo frente al linchamiento del Sur. Habiendo llegado al epicentro y salido con vida, Manuel renace a través de la militancia marxista y antirracista. Cuando le niegan servicio por ser negro en El Paso, responde que es un ciudadano extranjero que merece tratamiento justo. Le dicen, en español, que el restaurante no les sirve a los negros ni a los latinos. Por eso, él tiene una última mirada de la zona afectada antes de regresar a Colombia que es tan exasperante como la experiencia de Piri con la prostituta. Al final de He visto la noche, declara:

No había que huir de la medicina, sino complementarla agregando a los textos de patología aquellos capítulos no escritos de la realidad social que engendran la mayor parte de las enfermedades. Con este firme propósito regresé a México y como parte de esa medicina social denuncié en la prensa el oprobioso cáncer de la discriminación racial en los Estados Unidos, particularmente lo que había sufrido en mi tránsito por el Sur (403-404).

Así podemos apreciar el impacto profundo que tuvo su peregrinación en su visión hemisférica de la lucha contra el racismo.

\section{Cómo Streets ilumina el Sur en la ficción de Zapata}

Además del artículo antedicho y de sus relatos de viajes, el Sur es una zona de desastre en otras obras de Zapata, y éstas tienen paralelos con las memorias de Thomas. El linchamiento es el catalizador para la revolución en la obra de teatro Hotel de vagabundos (1955). Aunque el elenco de personajes es grande, se puede identificar a un afroamericano, Marcus, como el protagonista, ya que su lucha y muerte son la fuerza principal de la trama. El escenario es un hotel barato que se asemeja a un campo de refugiados. El "continental shift ['la deriva continental']", según Riofrío (2015: 12), incluye la itinerancia que viene de la migración -no sólo movimiento de tierra debajo de los pies de 
uno, sino pies moviendo sobre tierra, inmigrantes entrando a los Estados Unidos-. Los residentes pobres y vagabundos del hotel son veteranos o exiliados de ambas Guerras Mundiales, la Guerra Civil Española, la dictadura portuguesa y la lucha por la independencia en Puerto Rico. La conciencia de la violencia militar y terrorista crea una atmósfera de desarraigo e injusticia.

El hotel está en Manhattan, inspirado por la estancia de Zapata en Mill's Hotel de Harlem el año en que el drama tiene lugar, 1946 (Tillis, 2005). A pesar de estar en el Norte, Marcus sigue temiendo el linchamiento, ya que ha huido de Georgia después de casi ser ahorcado por coquetear con mujeres blancas. Por eso rehúsa llevar ropa limpia para no parecer presuntuoso y agarra su cuello repetidamente. Un hombre blanco acomodado, Mr. Callister, es ahorcado y robado después de que regala a Marcus una corbata usada. Un detective neoyorquino acusa a Marcus del crimen y es condenado a la silla eléctrica. Esta injusticia inspira a muchos otros residentes a marchar en protesta, pero la policía dispara a uno de ellosyarrojangases lacrimógenos alos protestantes cuando intentan revelar al verdadero asesino. Aunque Georgia es el epicentro, Nueva York tiene réplicas. Como hubiera sido en el Sur, se une una muchedumbre fuera del palacio de justicia para linchar al negro, y el juez condena a Marcus a retorcerse como una "lombriz", hasta reducirse a cenizas "negras como su alma" (1955: 95). La violencia institucional realizada en el cuerpo de Marcus desconstruye las imágenes de un Norte estable frente a un Sur monstruoso y revela un desastre racial que esconden el regionalismo estadounidense y la "armonía racial" latinoamericana.

La manifestación fracasada en el hotel despierta la conciencia revolucionaria de dos negros. El primero es un créole de Louisiana, Gino, quien cree que no es negro y por eso es superior a los personajes negros "de verdad" como el afroamericano Joe. Este último odia a Gino por intentar distanciarse de otros que Joe cree que pertenecen a la misma "raza". Joe explica esto a Oscar, un periodista negro de Sudamérica, que es el avatar del periodista Manuel. Oscar apunta la diferencia entre ser "negro" y ser un "nigger [sic] escapado de Louisiana" (el que niega su negritud) (83). Aunque Gino se ha convencido anteriormente que ha dejado la zona afectada en el Sur, en el Norte lo arrestan en una redada con el resto de los pobres y morenos del hotel por asociarse con Marcus. Gino y Joe son las fuentes que Oscar consulta sobre las diferencias entre los afroamericanos y también motivan a Oscar a identificar la identidad afro de algunos latinos. Está convencido de que los países latinoamericanos, a pesar 
de los desafíos a los negros cuando buscan trabajo, no discriminan contra los negros porque no los linchan. Por eso, cuando Joe chista que quiere linchar a todos los blancos, dice que sólo perdonaría a los latinos blancos. El diálogo exhibe latinidad hemisférica en la simultaneidad de los discursos latinoamericanos y estadounidenses sobre el racismo.

En Streets, Gerald Andrew West es la antítesis de Brew, como Gino lo es para Joe en Hotel. Luis alega que West es la personificación de Piri, pero yo lo veo como alguien que opta por no encarar el desastre del racismo y por eso no se ve como negro. West se ve como superior a Brew y a Piri, de la misma manera que Piri se sentía superior a Brew antes del viaje. West confiesa que él está escribiendo un libro sobre "el negro norteamericano" en el Sur desde un lugar muy cómodo en una ciudad de Virginia, lo que Brew considera cobarde (Thomas, 1967: 170). West fue criado en Pennsylvania, tiene piel clara y nunca había ido más hacia el Sur, así que ha podido convencerse de que el país está estable, a pesar de la violencia continua, tanto en el Sur como en el Norte. Brew detesta su impresión del supuesto joie de vivre de los negros y su visión antiséptica de la historia de la esclavitud. El negro auto-identificado se burla de la cobardía de West cuando éste alega que "by writing I will be fighting ['escribir es mi forma de luchar']", y porque West no se arriesga en la zona afectada (172).

Negar la negritud como cobarde en la falla geológica del Sur reaparece en el cuento "Un extraño bajo mi piel" (Zapata, 1967). ${ }^{13}$ El toque de queda para los negros hace de la Atlanta bajo Jim Crow como una ciudad bajo ley marcial. Al protagonista afroamericano, Elder, lo ataca una pandilla de blancos justicieros por violar el toque de queda. Los racistas lo atrapan en un baño mientras se preparan para ahorcarlo, lo que repetiría el linchamiento de su abuelo Arcie. ${ }^{14}$ Para sorpresa de Elder, él se emblanquece mágicamente, y cuando los atacantes regresan lo liberan. Como varios de los personajes negros mencionados, el nuevo Elder blanco, que se apoda "Ham Leroy," completa su transformación al escapar al Norte. Pero en Missouri todavía se siente paranoico de que su "negritud" sea descubierta y siente que su identidad se está desmoronando (1967, p. 145). Debe regresar al Sur para recuperar su negritud como Elder, un cambio de identidad que ocurre a medianoche, en el mismo lugar donde piensan ahorcarlo al principio del cuento.

\footnotetext{
${ }^{13}$ Cruz-Malavé (1997) interpreta el baño en la casa de Piri como un espacio paralelo con las "calles bravas" -en aquél, el sujeto masculino se "expulsa" de las identidades masculinas y nacionales hegemónicas (10)-. El personaje de Zapata también está al punto de ser expulsado de la sociedad blanca.

${ }^{14}$ Frazier Clemons (1993) alaba la obra por combatir la auto-negación entre negros.
} 
Elder/Ham no se siente en paz sin la certidumbre de encarar el peligro y su propio auto-odio.

El deseo de Zapata por solidaridad entre los grupos racializados y marginados, fortificada por su experiencia en el Sur de Jim Crow, influenciaría su representación de las relaciones raciales en su obra maestra, la saga Changó, el gran putas $(1983 ; 2010)$. En la sección "Ancestros combatientes", la heroína Agne Brown comienza como una niña negra que testimonia el linchamiento de su padre. Ella reprime este recuerdo traumático al principio de la novela, ya que le adopta el blanco y benévolo Reverend Robert. Éste la lleva a Lawrence, Kansas, mientras las escuelas integran a los blancos y a los negros, justo después del veredicto de Brown versus the Board of Education of Topeka. ${ }^{15}$ A pesar de ser rescatada de los tormentos del Sur, todavía encara las burlas crueles de sus compañeros de clase, lo que niega que el Sur tenga un monopolio de horror (Zapata, 2010, p. 527).

El miedo, sin embargo, no falta en Georgia. Se le acusa a su padre de acostarse con una enferma mental blanca, Josefa. Dos hombres lo ahorcan con la ayuda del alguacil y el suplente Clark, mientras que su hija los mira, paralizada. El "crimen" es que Josefa obliga al negro a tener relaciones con ella cuando él está obedientemente frotando sus piernas cojas con ungüento. El hermano de Josefa, Harry, se hace juez, jurado y verdugo. Desde la perspectiva de su padre infausto es como si un desastre natural lo hubiera matado, pero el desastre es el odio humano que Zapata retrata en su reportaje para que el lector juzgue a los responsables. Agne es ignorante de su negritud, como Piri al principio de Streets, hasta que, como Brew, su ancestro Zaca le recuerda los años de guerra entre las etnias norteamericanas. El linchamiento es un enlace con los primeros cautivos revoltosos que murieron luchando contra los esclavizadores y los sacerdotes. Los recuerdos resucitados de Agne comienzan con las imágenes de cadáveres colgados y carne carbonizada del Sur: una explosión de recuerdos traumáticos que irrumpen en el silencio.

Aunque hemos visto que hay factores colombianos que influencian la visión de la negritud de Zapata, Tillis (2005) considera su primera experiencia en los Estados Unidos, la génesis de su discurso racial sobre América, y Changó, su plenitud, una trayectoria difícil de negar. El escritor hace alusiones a los desastres del Sur durante toda su carrera, incluso en dos recopilaciones de ensayos. En

\footnotetext{
${ }^{15}$ Zapata enseñó literatura allí durante la época en que escribía Changó (Krakusin, 2001).
} 
Las claves mágicas de América (1989), el autor usa las cruces en llamas del K.K.K, que asocia con el Sur, como un ejemplo de cómo el cristianismo apoya el colonialismo y el racismo. Arguye que hay que encarar estos nexos históricos para redimir el Nuevo Mundo. En La rebelón de los genes (1997), Zapata recuerda el Sur como el lugar "donde linchaban a mis hermanos de etnia" (24), mostrando su solidaridad hemisférica y diaspórica con las víctimas de la crisis. Condena tanto la segregación racial estatal como la que propagan los justicieros, las que se radican en la violencia de los "colonizadores ingleses" (Ibíd.). No obstante, Zapata nota que actos de violencia parecidos a los de Estados Unidos ocurrieron en Latinoamérica y que la esclavitud continuó en Colombia después de la independencia. La solidaridad afro-latina que Zapata apoya en el Sur es hemisférica y abarca toda su obra.

\section{Implicaciones en relación con la situación contemporánea}

Las obras de Zapata y Thomas son importantes por estas y otras razones, y abren la discusión del racismo en América al nivel continental. Santiago-Díaz y Rodríguez (2009) han notado que la lucha de Piri por "descubrir" o "confesar" su "negritud" se corresponde con nuestra época de "color blindness", "ceguera al color-ignorar intencionalmente la diferencia racial" (1217). Martínez-San Miguel (2014) compara a Thomas con Fanon para mostrar que ambos interrumpen la "metropolitan masternarrative ['narrativa metropolitana predominante']" de una "post-racial society ['sociedad pos-racial']" (124). Argumentos espurios parecidos pueden aparecer en Colombia, donde trabajos académicos de especialistas en el tema afro se están creando para apoyar el reconocimiento de palenques y tierras indígenas. Ambos, Zapata y Thomas, buscan desestabilizar las estructuras que apoyan el racismo. Las obras de Zapata muestran que, por su experiencia en Estados Unidos, las leyes Jim Crow, el linchamiento y los movimientos de resistencia contra ellos eran continental shifts, "movimientos continentales", que crearon su afro-latinidad hemisférica. Por eso, el escritor está a la vanguardia de la generación de "turbulencia" de la literatura latina (1946-1974) (Stavans, 2010: 584). Sus textos muestran el papel que el Sur Norteamericano desempeñó en la formación de las identidades de dos de los escritores-activistas afro-latinos. Sus búsquedas por ver los desastres del racismo todavía son relevantes para las polémicas de hoy sobre la discriminación y violencia contra los negros por parte de la policía (Alexander, 2012; Riofrío, 2015). 
Como ocurre con los desastres causados por los humanos -el recalentamiento global y sus ramificaciones-, los políticos y los ciudadanos rehúsan todavía asumir la responsabilidad por sus papeles en causar y permitir que ocurran políticas y actos racistas. Vivimos al principio de la época Trump, en la que los grupos de odio norteamericanos se sienten envalentonados, el Estado discrimina abiertamente a los extranjeros -tanto en la prohibición de viajar para los musulmanes como en la propuesta de construir un muro en la frontera sureña-, y al lado de su fiscal general alabamiano, Jeff Sessions, se opone a investigaciones federales de violencia policial como la que resultó en la muerte de Freddie Gray y otros negros (Sanburn, 2017). Además de estas políticas retrógradas hacia las minorías raciales, Trump ha negado el calentamiento global, diciendo que es una mentira china (Baker \& Davenport, 2017). El espíritu de la época durante la juventud de Thomas y Zapata ha irrumpido en el hemisferio con furia en 2017 y todavía no hemos visto todas las réplicas. Si los americanos, tanto del norte como del sur, siguen negando la realidad de la violencia contra nuestra tierra y nuestros propios pueblos, si seguimos siendo pasivos y no nos lanzamos a las zonas afectadas, el futuro será tan horripilante como el desastre de Jim Crow.

\section{Bibliografía}

Alexander, M. (2012). The New Jim Crow: Mass Incarceration in the Age of Colorblindness. New York: The New Press.

Arbeláez, O. (2006). “Un vagabundo en los Estados Unidos”, Estudios de Literatura Colombiana, no 18 pp. 1-40.

Baker, P., \& Davenport, C. (2017, 24 enero). "Trump Revives Keystone Pipeline Rejected by Obama". The New York Times: http:// www.nytimes.com/2017/01/24/us/politics/keystone-dakotapipeline-trump.html [Consultado el 28 de marzo de 2017].

Bethell, L. (2010). "Brazil and 'Latin America' ", Journal of Latin American Studies, no 42, pp. 457-485.

Branche, J. (2008). Race, Colonialism, and Social Transformation in Latin America and the Caribbean. Gainesville: University Press of Florida.

Brown, D. (2017, 1 junio). “'Life or Death for Black Travelers': How Fear Led to 'The Negro Motorist Green-Book.', The Washington Post: https://www.washingtonpost.com/news/retropolis/ wp/2017/06/01/life-or-death-for-black-travelers-how-fear-ledto-the-negro-motorist-green-book/?utm_term=.f95cc22773b6 [Consultado el 22 de junio de 2017].

Caminero-Santangelo, M. (2004). 'Puerto Rican Negro': Defining Race in Piri Thomas's Down These Mean Streets, MELUS, vol. XXIX, no 2, pp. 206-226. 
(2007). On Latinidad: US Latino Literature and the Construction of Ethnicity. Gainesville: UP of Florida.

Cohn, D. (2007). "U.S. Southern and Latin American Studies: Postcolonial and Inter-American Approaches", The Global South, vol. I, no 1, pp. 38-44.

Cruz-Malavé, A. (1997). “'What a Tangled Web... !': masculinidad, abyección y fundación en la literatura puertorriqueña en los Estados Unidos", Revista de Crítica Literaria Latinoamericana, vol. XXIII, no 45, pp. 327-340.

. (2012). "The Antifoundational Foundational Fiction of Piri Thomas (1928-2011)", Centro Journal, vol. 24, no 1, pp. 4-19.

Dalleo, R., \& Machado Sáez, E. (2007). The Latino/a Canon and the Emergence of Post-Sixties Literature. Nueva York: Palgrave Macmillan.

Davis, F.J. (1994). Who is Black? One Nation's Definition. (10). University Park: Pennsylvania State University Press.

Dhouti, K. (2007). Reconfiguring Mestizaje: Black Identity in the Works of Piri Thomas, Manuel Zapata Olivella, Nicolás Guillén, and Nancy Morejón: https://repositories.lib.utexas.edu/ handle/2152/10957 [Consultado el 28 de marzo de 2017]. .Martínez. (2007). "Rewriting the Other: Manuel Zapata Olivella's ¡Levántate Mulato!”, Letras Hispanas, vol. IV, nº 2, pp. 129-137.

Di Iorio Sandín, L. (2004). Killing Spanish: Literary Essays on Ambivalent U.S. Latino/a Identity. Palgrave Macmillan.

Duany, J. (2000, 10-12 febrero). "Neither Black nor White: The Politics of Race and Ethnicity among Puerto Ricans on the Island and in the U.S. Mainland". En The Meaning of Race and Blackness in the Americas: Contemporary Perspectives Conference. Brown U, Providence, Rhode Island: http://maxweber.hunter.cuny.edu/ pub/eres/SOC217_PIMENTEL/duany.pdf [Consultado el 28 de marzo de 2017].

Equal Justice Initiative. (2014). "Lynching in America: Confronting the Legacy of Racial Terror": http://eji.org/reports/lynching-inamerica [Consultado el 8 de junio de 2015].

Flores, J. (2009). The Empire Strikes Back: Caribeño Tales of Learning and Turning. Nueva York: Routledge.

Flórez Bolívar, F.J. (2015). "Un diálogo diaspórico: el lugar del Harlem Renaissance en el pensamiento racial e intelectual afrocolombiano (1920-1948)", Historia Crítica, no 55, pp. 101-124.

Frazier Clemons, B. (1983). “Manuel Zapata Olivella's 'Un extraño bajo mi piel': A Study of Repression", Afro-Hispanic Review, vol. II, no 3, pp. 5-7.

Freyre, G. (1938). Casa-grande e senzala: Formação da família brasileira sob o regime de economia patriarchal. Rio de Janeiro: Schmidt Editor.

Garland Mahler, A. (2015). "The Global South in the Belly of the Beast", Latin American Research Review", vol. L, no 1, pp. 97-116. 
Griffith, F. (1995).“Who Set You Flowin'?”: The African-American Migration Narrative. New York: Oxford University Press.

Hernández, C. D. (1997). Puerto Rican Voices in English: Interviews with Writers. Westport: Praeger.

Jiménez Román, M., \& Flores, J. (Eds.) (2010). The Afro-Latin@ Reader: History and Culture in the United States. Durham: Duke University Press.

Kanellos, N. (Ed.). (2016). Recovering the US Hispanic Literary Heritage Project: https://artepublicopress.com/recovery-project [Consultado el 1 de agosto de 2016].

Krakusin, M. (2001). Conversación informal con Manuel Zapata Olivella. Afro-Hispanic Review, vol. XX, no 1, pp. 15-28.

Luis, W. (1997). Dance Between Two Cultures: Latino Caribbean Literature Written in the United States. Nashville: Vanderbilt University Press.

(1998). "Black Latinos Speak: The Politics of Race in Piri Thomas's

Down These MeanStreets", Indiana Journal of Hispanic Literatures, vol. XII, no 27-49.

(2006). Afro-Cuban/Latino Identity. Black Renaissance/Renaissance Noir, vol. VI-VII, no 3/1, pp. 145-151.

. (2012). "Afro-Latino/a Literature and Identity". En S. Bost \& F.R. Aparicio (Eds). The Routledge Companion to Latino/a Literature. (34-45). Londres: Routledge.

Martínez-San Miguel, Y. (2014). Coloniality of Diasporas: Rethinking IntraColonial Migrations in a Pan-Caribbean Context. Nueva York: Palgrave Macmillan.

McGill, L. (2002). "A Conversation with Piri Thomas", Bilingual Review/La Revista Bilingüe, vol. XXV, no 2, pp. 179-184.

Medina-Rivera, A. (2003). "El proceso de convertirse en hombre en las historias de Piri Thomas y Pedro Juan Soto", Hispania, vol. LXXXVI, no 4, pp. 898-906.

Mina Aragón, W. (2016). Manuel Zapata Olivella: Un legado intercultural. Bogotá: Desde Abajo.

New York Public Library. (2017). The Green Book: https://digitalcollections. nypl.org/collections/the-green-book\#/?tab=about [Consultado el 29 de marzo de 2017].

Oboler, S. (1995). Ethnic Labels, Latino Lives: Identity and the Politics of (Re) Presentation in the United States. University of Minnesota Press.

Olliz Boyd A. (1992). "Manuel Zapata Olivella”. En W. Luis \& González, A. (Eds.) Dictionary of Literary Biography: Modern Latin-American Fiction Writers. Detroit: Gale Research, vol. CXIII, pp. 313-322.

Omi, M., \& Winant, H. (1986). Racial Formation in the United States from the 1960 s to the 1980s. Nueva York: Routledge.

Orozco, W. (2012). He visto la noche de Manuel Zapata Olivella: El viaje de un marginal en búsqueda de sus raíces. Estudios de Literatura Colombiana, nํㅜ 31, pp. 267-273. 
Ortiz, F. (2002). Contrapunteo cubano del tabaco y el azúcar. Advertencia de sus contrastes agrarios, económicos, históricos y sociales, su etnografía y su transculturación. (Ed. E.M. Santí). Madrid: Cátedra.

Palacios Palacios, G. (2015). "Apuntes sobre la música, el folclor, lo nacionalpopular y la literatura en algunos de los escritos tempranos de Manuel Zapata Olivella”, Escritos, vol, XXIII, no 51, pp. 439-470.

Prescott, L. (2000). "Presentación”. En Zapata Olivella, M. Pasión Vagabunda. Bogotá: Ministerio de Cultura, pp. 229-239.

(2007). "Journeying through Jim Crow: Spanish American Travelers in the United States during the Age of Segregation", Latin American Research Review, XLII, no 1, pp. 3-28.

Riofrío, J. D. (2015). Continental Shifts: Migration, Representation, and the Struggle for Justice in Latin(o) America. Austin: University of Texas Press.

Rivera-Rideau, P.R., Jones, J.A. \& Paschel, T.S. (2016). Afro-Latin@s in Movement: Critical Approaches to Blackness and Transnationalism in the Americas. Nueva York: Palgrave.

Roberts, S. (1995, 5 Febrero). The 10 Best Books about New York. The New York Times: http://www.nytimes.com/books/97/09/07/home/ newyork-10best.html [Consultado el 24 de julio de 2015].

Rodríguez, C. (2000). Changing Race: Latinos, the Census, and the History of Ethnicity in the United States. Nueva York: New York UP.

Sanburn, J. (2017, 20 enero). "President Trump Just Signaled Some Dramatic Changes for Police and Criminal Justice”, Time: http://time. com/4641374/trump-inuaguration-police-protestors-justice [Consultado el 28 de marzo de 2017].

Sánchez, M.E.(2005). “Shakin'Up” Race and Gender: Intercultural Connections in Puerto Rican, African American, and Chicano Narratives and Culture (1965-1995). Austin: University of Texas Press.

Sánchez, R., \& Pita, B. (2006). Theses on the Latino Bloc: A Critical Perspective. Aztlán: A Journal of Chicano Studies, vol. XXXI, no 2 , pp. 25-33.

Santiago-Díaz, E., \& Rodríguez, I. (2009). "Desde las fronteras raciales de dos casas letradas: Habla Piri Thomas", Revista Iberoamericana, LX, n 229, pp. 119-121.

Stavans, I. (Ed.). (2010). The Norton Anthology of Latino Literature. Nueva York: W.W. Norton and Company.

Taylor, C. (2017). Green Book Project: http://time.com/4641374/trumpinuaguration-police-protestors-justice [Consultado el 22 de junio de 2017].

Thomas, P. (1967). Down These Mean Streets. Nueva York: Knopf.

. [Tomás]. (1998). Por estas calles bravas. Nueva York: Vintage (Traducción de Suzanne Dod Tomás).

Tillis, A. (2005). Manuel Zapata Olivella and the "Darkening" of Latin American Literature. Columbia: University of Missouri Press. 
Valero, S. (2013). "¿De qué hablamos cuando hablamos de 'literatura afrocolombiana'? o los riesgos de las categorizaciones", Estudios de Literatura Colombiana, no 32, pp. 15-37.

Vasconcelos Calderón, J. ([1925]. 1966). La raza cósmica: Misión de la raza iberoamericana, Argentina y Brasil. México: Espasa-Calpe.

Wade, P. (1995). The Cultural Politics of Blackness in Colombia. American Ethnologist , vol. XXII, no 2, pp. 341-357: http://personalpages. manchester.ac.uk/staff/peter.wade/articles/AE\%20paper.pdf [Consultado el 29 de marzo de 2017].

Wilkerson, I. (2010). The Warmth of Other Suns: The Epic Story of America's Great Migration. New York: Vintage.

Zapata Olivella, M. [Manuel Karabalí]. (Sin fecha.) "Un colombiano en la tierra del Ku-Klux-Klan". Nashville, Tennessee: Manuel Zapata Olivella Archives, Vanderbilt University Heard Library Special Collections, 8p.

. (1955). Hotel de vagabundos (teatro). Bogotá: Espiral, 1955.

. (1967). “Un extraño bajo mi piel”. En Zapata Olivella, M. ¿Quién le dio el fusil a Oswald? y otros cuentos. Bogotá: Editorial Revista Colombiana, pp. 134-147.

. (1989). Las claves mágicas de América. Bogotá: Plaza \& Janés. - (1990). ¡Levántate mulato! Por mi raza hablará el espíritu. Bogotá: REI Andes.

- (1997). La rebelión de los genes: el mestizaje americano en la sociedad futura. Bogotá: Altamir.

- (2000). "He visto la noche". En Zapata Olivella, M. Pasión vagabunda. Bogotá: Ministerio de Cultura, pp. 241-404.

. (2009). Changó, the Biggest Badass. Lubbock: Texas Tech University Press. (Traducción de Jonathan Tittler).

. Changó, el gran putas. (2010). Bogotá: Ministerio de Cultura de Colombia: http://www.banrepcultural.org/sites/default/ files/88094/03-Manuel_Zapata_Chango_el_gran_putas.pdf [Consultado el 30 de marzo de 2017]. 